\title{
Low thermal expansion modulated by off-stoichiometric effect in nonstoichiometric Laves phase $\mathrm{Hf}_{0.87} \mathrm{Ta}_{0.13} \mathrm{Fe}_{2+x}$ compounds
}

Longfu Li, ${ }^{\dagger, \downarrow}$ Peng Tong, ${ }^{* \dagger, \dagger}$ Wei Tong, ${ }^{\S}$ Weibin Jiang,,${ }^{\dagger}$ Yanwei Ding,,${ }^{\ddagger}$ He Lin, ${ }^{\perp}$ Jianchao Lin, ${ }^{\dagger}$ Cheng Yang, ${ }^{\dagger}$ Feng Zhu,,${ }^{\dagger,}$ Xuekai Zhang, ${ }^{\dagger,}{ }^{\dagger}$ Xuebin Zhu, ${ }^{\dagger}$ Wenhai Song, ${ }^{\dagger}$ and Yuping $\operatorname{Sun}^{*, \S, \uparrow}$

${ }^{\dagger}$ Key Laboratory of Materials Physics, Institute of Solid State Physics, Chinese Academy of Sciences, Hefei, 230031, PR China

\#niversity of Science and Technology of China, Hefei, 230026, PR China

${ }^{\S}$ Anhui Province Key Laboratory of Condensed Matter Physics at Extreme Conditions, High Magnetic Field Laboratory, Chinese Academy of Sciences, Hefei, 230031, PR China ${ }^{\perp}$ Shanghai Institute of Applied Physics, Chinese Academy of Sciences, Shanghai, 200120, PR China

${ }^{*}$ Corresponding authors.

E-mail addresses: tongpeng@issp.ac.cn (P. Tong), ypsun@issp.ac.cn (Y.P. Sun). 



Figure S1. (a) XRD patterns at room temperature for $\mathrm{Hf}_{0.87} \mathrm{Ta}_{0.13} \mathrm{Fe}_{2+x}(0 \leq x \leq 1.5)$ samples.

(b) The refined lattice constants $a, b, c$ and unit cell volume as a function of $x$ values $(0.05$ $\leq x \leq 0.45)$. The lines are guides for the eye.
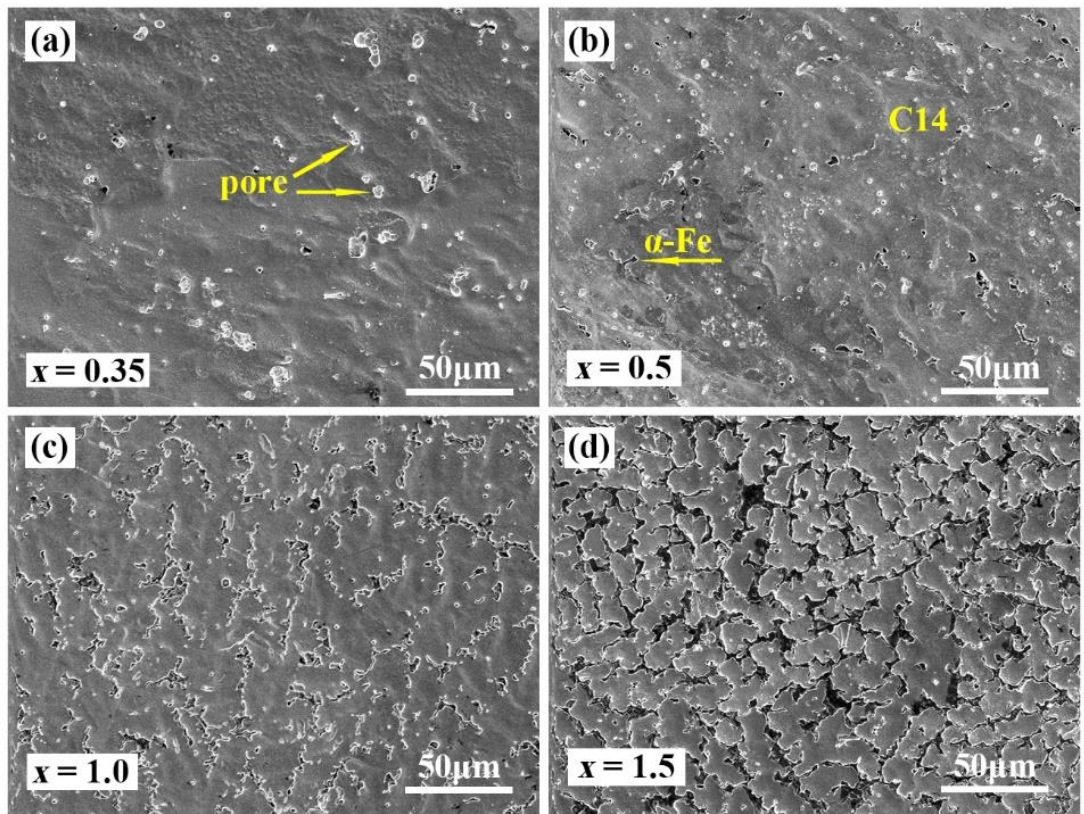

Figure S2. SEM images of $\mathrm{Hf}_{0.87} \mathrm{Ta}_{0.13} \mathrm{Fe}_{2+x}(x=0.35,0.5,1.0$ and 1.5). The dark irregular grains and the gray areas represent the $\alpha-\mathrm{Fe}$ phase and the matrix of $\mathrm{C} 14$ Laves phase structure, respectively. 




Fig. 3. (a) Micrograph of selected area in $\mathrm{Hf}_{0.87} \mathrm{Ta}_{0.13} \mathrm{Fe}_{3.0}$. The EDS mapping of selected area for different elements: (b) Hf, (c) Ta and (d) Fe.
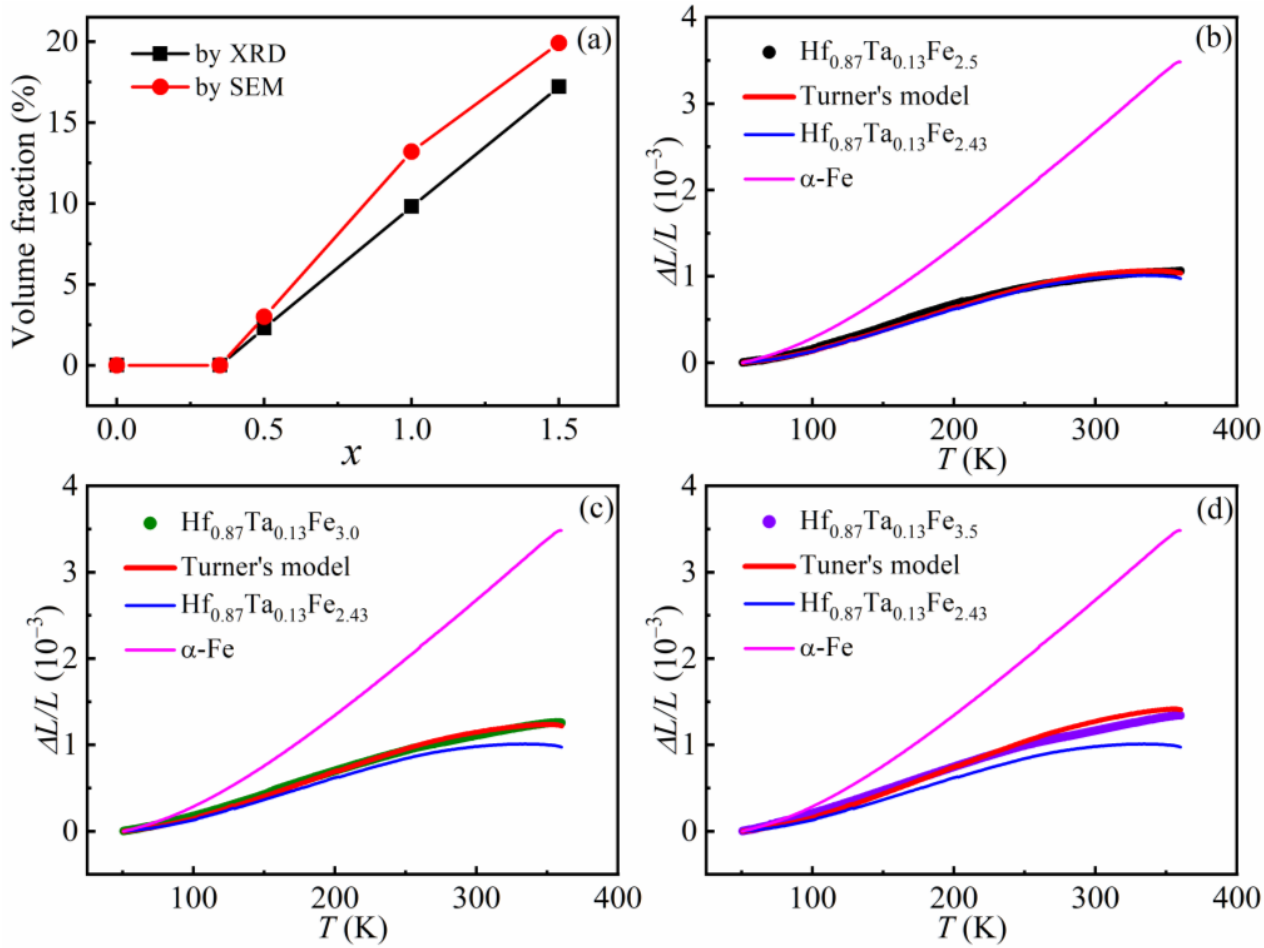

Figure S4. (a) Volume fractions of $\alpha-\mathrm{Fe}$ phase with respect to $x$ values obtained respectively from XRD patterns and SEM images. Curves of linear thermal expansion obtained from experiments and plots calculated by Turner's model for (b) $\mathrm{Hf}_{0.87} \mathrm{Ta}_{0.13} \mathrm{Fe}_{2.5}$, (c) $\mathrm{Hf}_{0.87} \mathrm{Ta}_{0.13} \mathrm{Fe}_{3.0}$ and (d) $\mathrm{Hf}_{0.87} \mathrm{Ta}_{0.13} \mathrm{Fe}_{3.5}$, respectively. 
Turner's model takes into consideration mechanical interaction by assuming each element of the composite is constrained to change in dimension at the same rate. ${ }^{1}$ Hence, the coefficient of thermal expansion (CTE) of two-component composites found in Turner's model are as follows: $\alpha_{\mathrm{c}}=\left(V_{1} K_{1} \alpha_{1}+V_{2} K_{2} \alpha_{2}\right) /\left(V_{1} K_{1}+V_{2} K_{2}\right)$, where $V_{\mathrm{i}}, K_{\mathrm{i}}$ and $\alpha_{\mathrm{i}}$ are the volume fraction, the bulk modulus and the CTE of each component of the composite, respectively. ${ }^{1}$ The bulk modulus $K$ is related to the elastic modulus $E$ and Poisson's ratio $v$ by the relation, $K=E / 3(1-2 v)$. Poisson's ratio for $\alpha-\mathrm{Fe}$ (iron) and $\mathrm{Hf}_{1-x} \mathrm{Ta}_{x} \mathrm{Fe}_{2}$ compound are 0.295 and 0.32 , respectively. ${ }^{2,3}$ As mentioned in our previous work, the Young's modulus for all $\mathrm{Hf}_{1-x} \mathrm{Ta}_{x} \mathrm{Fe}_{2}$ compositions investigated are larger than 220GPa. ${ }^{3}$ The Young's modulus of $\alpha$-Fe is $204 \sim 212 \mathrm{GPa},{ }^{2}$ rather close to that of $\mathrm{Hf}_{1-x} \mathrm{Ta}_{x} \mathrm{Fe}_{2}$ compositions. Then, by assuming an estimated Young's modulus of $200 \mathrm{GPa}$ for $\mathrm{Hf}_{0.87} \mathrm{Ta}_{0.13} \mathrm{Fe}_{2.43}$, we can simplify the Turner's model in the $x \geq 0.5$ compounds as follows by approximation: $\alpha_{\mathrm{c}}=v_{1} E_{1} \alpha_{1}+v_{2} E_{2} \alpha_{2}$. 

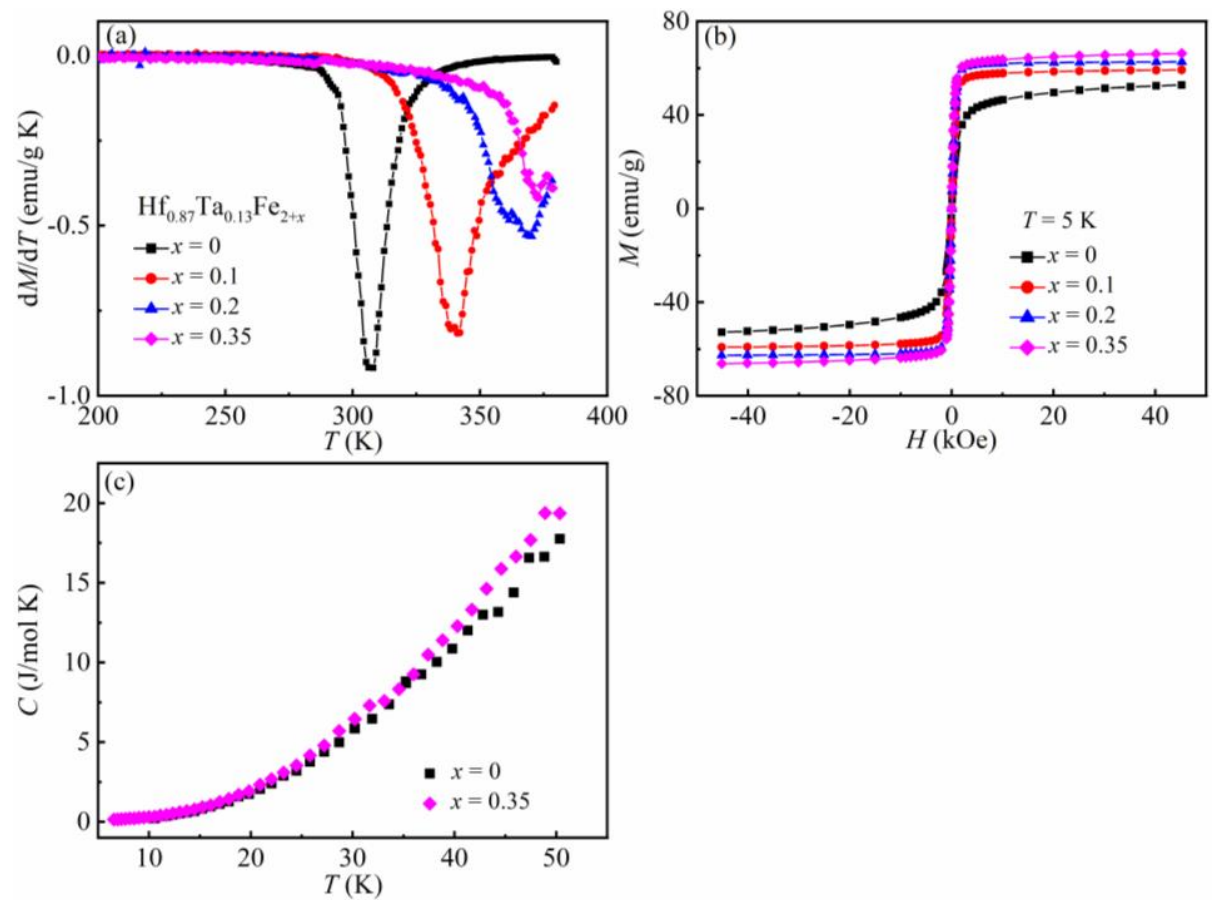

Figure S5. (a) $\mathrm{d} M / \mathrm{d} T$ of $\mathrm{Hf}_{0.87} \mathrm{Ta}_{0.13} \mathrm{Fe}_{2+x}(x=0,0.1,0.2$ and 0.35$)$ recorded at a magnetic field of 500 Oe under zero-field-cooling (ZFC) mode. (b) Isothermal magnetization recorded at $5 \mathrm{~K}$ for $x=0,0.1,0.2$ and 0.35 . (c) Specific heat for $x=0$ and 0.35. (d) SEM images of $\mathrm{Hf}_{0.87} \mathrm{Ta}_{0.13} \mathrm{Fe}_{3.0}$ subjected to 100 thermal cycles. 

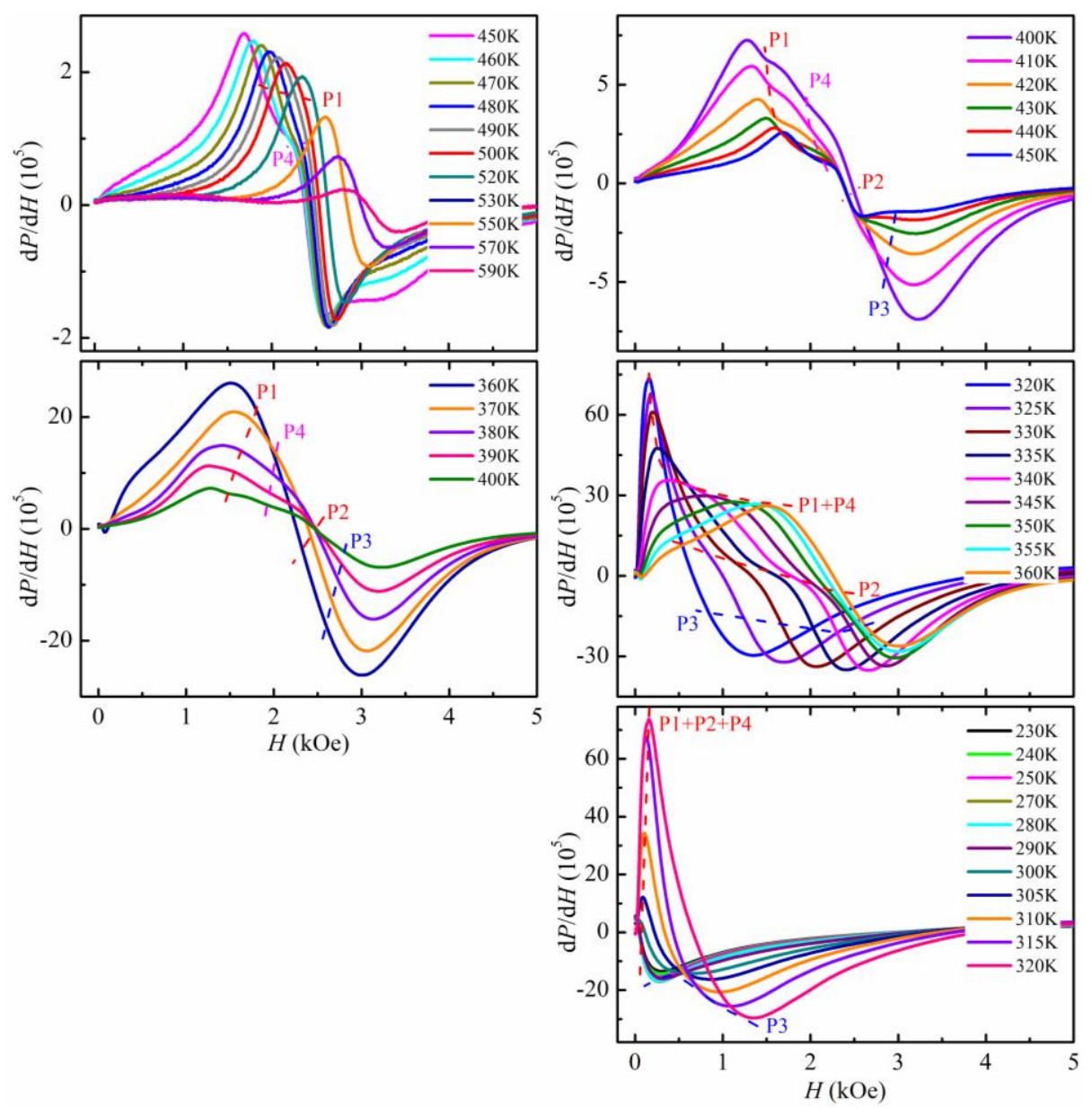

Figure S6. Original ESR data for $\mathrm{Hf}_{0.87} \mathrm{Ta}_{0.13} \mathrm{Fe}_{2.1}$ without any treatments. 

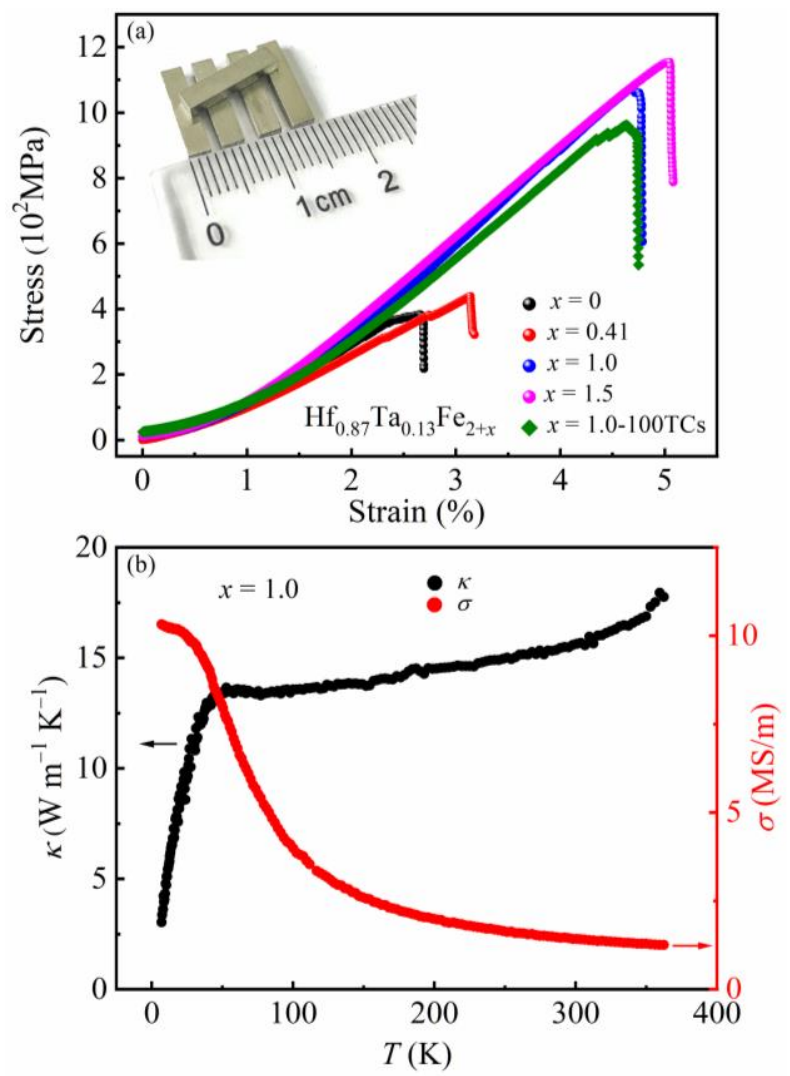

Figure S7. (a) The stress-strain curves of compression measurement. For comparison, the data of $\mathrm{Hf}_{0.87} \mathrm{Ta}_{0.13} \mathrm{Fe}_{2}$ (from Ref. 3) is shown. The inset displays photograph of $x=1.0$ specimens. The compressive strength of $x=1.0$ subjected to 100 thermal cycles (TCs) is also displayed. (b) Temperature dependence of thermal and electrical conductivities for $\mathrm{Hf}_{0.87} \mathrm{Ta}_{0.13} \mathrm{Fe}_{3.0}$ sample.

In terms of practical applications, it is advantageous and highly desirable that lowCTE materials possess high thermal conductivity in order to achieve thermal homogeneity and avoid thermal stress. Besides, since $\mathrm{Hf}_{0.87} \mathrm{Ta}_{0.13} \mathrm{Fe}_{2+x}$ is intermetallic compound, the electrical conductivity is an important parameter with respect to the possible use in electrical devices. Hence, $x=1.0$ was chosen for thermal and electrical conductivity measurements, and the results are displayed in Figure S7b. The inclusion of only 9.8 vol.\% 
$\alpha$-Fe results in a high thermal conductivity $(\kappa)$ of $15.6 \mathrm{~W} \cdot \mathrm{m}^{-1} \cdot \mathrm{K}^{-1}$, which is $50 \%$ larger than that of $x=0\left(10.1 \mathrm{~W} \cdot \mathrm{m}^{-1} \cdot \mathrm{K}^{-1}\right)$ and Invar $36\left(10.4 \mathrm{~W} \cdot \mathrm{m}^{-1} \cdot \mathrm{K}^{-1}\right) \cdot{ }^{4}$ Furthermore, such a value is beyond those of other metal-matrix composites such as $6 \mathrm{~W} \cdot \mathrm{m}^{-1} \cdot \mathrm{K}^{-1}$ for dual phase $\mathrm{LaFe}_{13.9} \mathrm{Si}_{1.4} \mathrm{H}_{y}$ and $7.5 \mathrm{~W} \cdot \mathrm{m}^{-1} \cdot \mathrm{K}^{-1}$ for metal-bonded $\mathrm{La}(\mathrm{Fe}, \mathrm{Mn}, \mathrm{Si}){ }_{13} \mathrm{H}_{x}$ composite. ${ }^{5,6}$ As mentioned above, the pores exist in $x=0$ and 0.35 samples, but are much reduced in the samples with precipitates. The enhancement of thermal conductivity is ascribed to relatively higher thermal conductivity of $\alpha-\mathrm{Fe}\left(80.2 \mathrm{~W} \cdot \mathrm{m}^{-1} \cdot \mathrm{K}^{-1}\right)$ and filling up the pores in the matrix by $\alpha-\mathrm{Fe}^{4}$ The electrical conductivity of $x=1.0$ is a characteristic of metals. The $\sigma$ at RT is $1.43 \mathrm{MS} / \mathrm{m}$. Such a high $\sigma$ value exceeds that of Invar 36 alloy $(1.19 \mathrm{MS} / \mathrm{m}),{ }^{4}$ and is close to that of Kovar alloy $(2.0 \mathrm{MS} / \mathrm{m})^{7}$

\section{References}

(1) Turner, P. S. The problem of thermal-expansion stresses in reinforced plastics. J. Res. NBS 1946, 37, 239.

(2) https://www.azom.com/properties.aspx?ArticleID=619.

(3) Li, L. F.; Tong, P.; Zou, Y. M.; Tong, W.; Jiang, W. B.; Jiang, Y.; Zhang, X. K.; Lin, J. C.; Wang, M.; Yang, C.; Zhu, X. B.; Song, W. H.; Sun, Y. P. Good comprehensive performance of Laves phase $\mathrm{Hf}_{1-x} \mathrm{Ta}_{x} \mathrm{Fe}_{2}$ as negative thermal expansion materials. Acta Mater. 2018, 161, 258-265.

(4) Martienssen, W.; Warlimont, H. Springer Handbook of Condensed Matter and Materials Data. Spinger; 2005. p. 133-783. 
(5) Shao, Y. Y.; Liu, J.; Zhang, M. X.; Yan, A.; Skokov, K. P.; Karpenkov, D. Y.; Gutfleisch, O. High-performance solid-state cooling materials: Balancing magnetocaloric and non-magnetic properties in dual phase La-Fe-Si. Acta Mater. 2017, 125, 506-512.

(6) Radulov, I. A.; Karpenkov, D. Y.; Skokov, K. P.; Karpenkov, A. Y.; Braun, T.; Brabänder, V.; Gottschall, T.; Pabst, M.; Stoll, B.; Gutfleisch, O. Production and properties of metal-bonded $\mathrm{La}(\mathrm{Fe}, \mathrm{Mn}, \mathrm{Si}){ }_{13} \mathrm{H}_{x}$ composite material. Acta Mater. 2017, 127, 389-399. https:/edfagan.com/expansion-electronic-refractory-soft-magnetic-alloysliterature.php. 